\title{
Recurrent Cerebral Infarction during Anticoagulation Therapy in Patients with Mitral Valve Prolapse
}

\author{
Ashfaq Shuaib and William F. Murphy
}

\begin{abstract}
Mitral valve prolapse has been associated with an increased risk of transient or lasting ischemic events. Recurrence is uncommon after initiation of antiplatelet or anticoagulant therapy. In this communication we report two patients, both female, who had mitral valve prolapse as the major risk factor for cerebrovascular disease and who developed cerebral infarction despite anticoagulation. The cerebral infarctions were bilateral and extensive in one patient and led to the patient's death. In the second case, three infarctions resulted in moderate disability.
\end{abstract}

\begin{abstract}
RÉSUMÉ: Infarcissement cérébral récurrent pendant l'anticoagulothérapie chez les patients ayant un prolapsus de la valvule mitrale. Le prolapsus de la valvule mitrale a été associé à un risque accru d'événements ischémiques transitoires ou permanents. Une récidive est inhabituelle après l'institution d'une thérapie antiplaquettaire ou d'une anticoagulothérapie. Dans cet article, nous rapportons les cas de deux patients, toutes deux des femmes, qui avaient un prolapsus de la valvule mitrale comme facteur de risque important de la maladie cérébrovasculaire et qui ont développé un infarctus cérébral en dépit de l'anticoagulothérapie. Les infarcissements étaient bilatéraux et étendus chez une patiente et ont provoqué son décès. Dans le second cas, trois infarcissements ont donné lieu à une invalidité modérée.
\end{abstract}

Can. J. Neurol. Sci. 1991; 18: 137-139

In 1976, Barnett et al reported that mitral valve prolapse (MVP) may be a potential source for cerebral ischemic events. 1 A recent review analyzed 114 patients with MVP and cerebral events from 6 studies. $^{2}$ Cerebral infarctions occurred in twothirds of the cases and the remainder had transient ischemic attacks. Recurrent events were seen in $20 \%$ of cases, with recurrences occurring within months to several years after the initial event. Embolic episodes after initiation of anticoagulant therapy was not commented upon.

Autopsy reports on patients with mitral valve prolapse and stroke are rare. ${ }^{3-6}$ One patient had systemic carcinoma and another patient, 5 atrial fibrillation, in addition to the mitral valve prolapse. $^{4}$

In this communication we report two patients with MVP who developed recurrent cerebral infarctions despite adequate anticoagulation. One patient was severely disabled from large bilateral infarctions and died while the second patient made a moderate recovery after three cortical infarctions.

\section{Case Reports}

\section{Patient 1}

This 33-year-old female was initially assessed three years ago for a sudden onset of blurred vision. Neurological examination at that time had shown a right homonymous hemianopia and the remainder of the examination was normal. Cranial CT scan showed a hemorrhagic cerebral infarction in the left occipital lobe (Figure 1). Two-dimensional echocardiography (2-DE) showed MVP. All remaining investigations including cerebral angiography, collagen disease work up and hematological studies were normal. There was no evidence for cortical vein thrombosis. The patient was discharged on ASA. Two weeks later the patient presented to the Emergency Room with a focal seizure. Examination showed an upper motor neuron type weakness on the left side. Cranial CT scan showed a new hemorrhagic infarction in the right parietal lobe (Figure 2). The patient was anticoagulated in hospital and discharged after the weakness improved. The patient remained symptom-free on anticoagulants for two years. Her final admission was for a six day episode of clumsiness of the left hand. Repeated CT scan showed a new cerebral infarction of the right parietal lobe (see Figure 3). Prothrombin time was one and one-half times normal. A repeated 2DE showed significant myxomatous degeneration of the mitral valve leaflets. During this admission, the anticoagulants were increased to keep the prothrombin time at two and one-half times normal. Her symptoms gradually resolved and she has remained symptom-free on the higher dose anticoagulants.

\section{Patient 2}

This 42-year-old female was initially seen for recent onset of dizziness. Holter monitor showed intermittent atrial fibrillation. The patient was treated with digoxin to control the ventricular rate.

Two months later the patient developed a sudden speech deficit and right-sided body weakness. Examination revealed global aphasia, right-

From the Department of Medicine (Neurology), University Hospital, Saskatoon, (A.S.) and the Calgary General Hospital, Calgary (W.F.M.) Received July 18, 1990. Accepted in final form October 29, 1990

Reprint requests to: Dr. Ashfaq Shuaib, Department of Medicine, Royal University Hospital, Saskatoon, Saskatchewan, Canada S7N 0X0 
sided upper motor neuron type weakness and right homonymous hemianopia. Cranial CT revealed a large infarction in the left cerebral hemisphere in the middle cerebral artery territory distribution. Two-DE showed MVP and a repeated Holter in hospital showed frequent pauses in the cardiac rhythm. The episodes of intermittent atrial fibrillation and asystoles were diagnosed as sick sinus syndrome and a permanent cardiac pacemaker was inserted. Although no thrombus was seen on the 2$\mathrm{DE}$, the patient was anticoagulated. After insertion of the pacemaker, no rhythm problems were observed.

Two months after the initial infarction, the patient experienced a generalized tonic clonic seizure and subsequently failed to wake up. Repeated examination showed new left-sided weakness and a second cranial CT showed a new right parieto-frontal cerebral infarction. Prothrombin time was slightly over one and one-half times control.

The patient remained in a chronic vegetative state for four weeks and then died from pneumonia. At autopsy both cerebral infarctions were clearly visible in the middle cerebral artery territories. Blood clots were present in the right carotid and both middle cerebral arteries. Gross and microscopic examination was consistent with embolic material from a more proximal source. No atheromatous lesions or ulcers were seen in the carotids or other major blood vessels. Examination of the heart revealed no vegetations on the valves and examination of the atrium and ventricles showed no clots. Microscopic examination showed typical myxomatous degeneration of the mitral valve. Chordae tendinae were intact and excessive fibrosis of the endothelial covering was not apparent.

\section{Discussion}

Most patients with MVP and cerebral events have a good prognosis and do not have recurrent symptoms especially after anticoagulation. Our two cases had a different course. In one case we could identify MVP as the only risk factor for the cerebral infarction. In the second patient, a cardiac rhythm problem could also have contributed to the cerebral infarction. Although the autopsy did not show vegetations on the mitral valve in the second case, the clinical course and the presence of clots in the cerebral arteries was very suggestive of embolic infarctions.

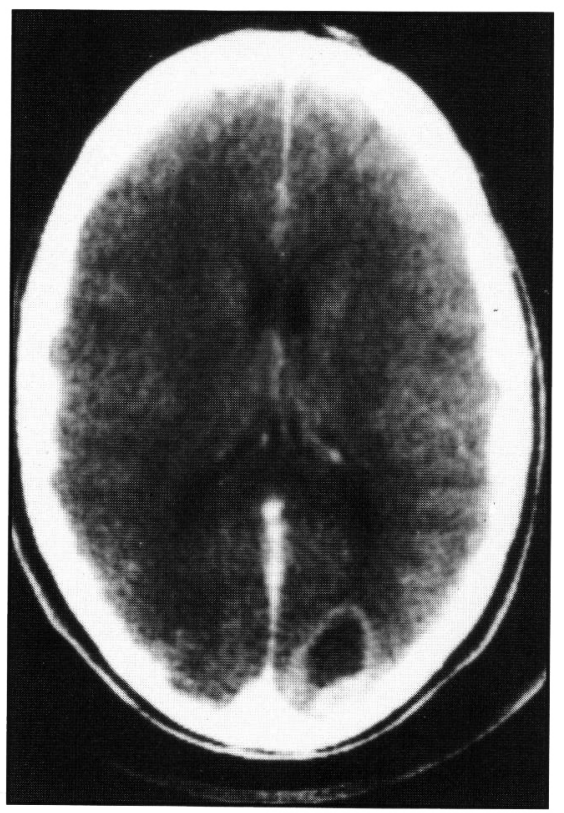

Figure I - Cranial CT scan of the first patient during the initial admission. There is a hemorrhagic infarction in the left occipital lobe.
Mechanisms for cerebral infarction in patients with MVP and no other etiology remain unclear. The most likely cause appears to be a nonbacterial thrombus originating and embolizing from the mitral valve. ${ }^{7}$ As the normal valve is replaced by myxoma-

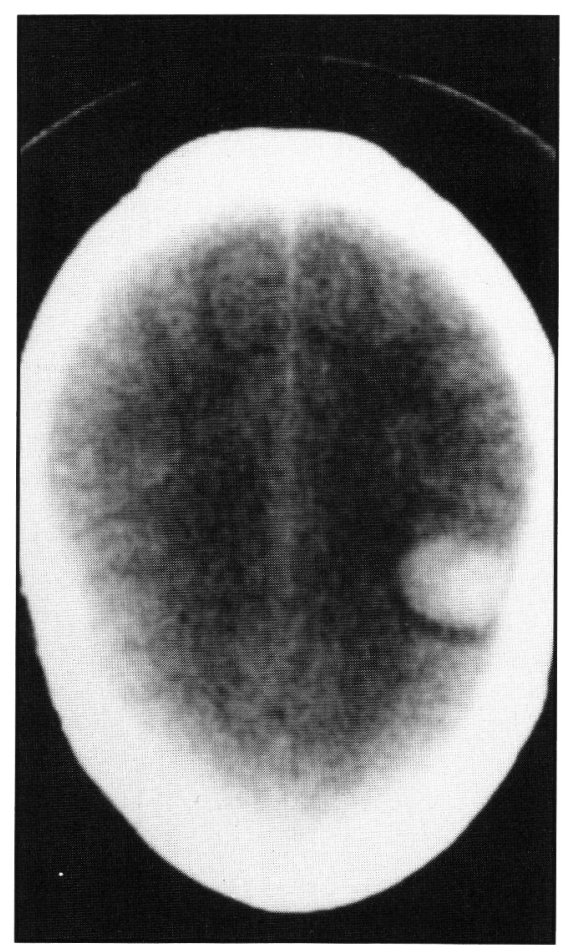

Figure 2 - The second cranial CT was done after the patient presented with a seizure. This show's a new cerebral infarction in the left parietal region just proximal to the previous infarction. The hemorrhage from the previous infarction has now cleared up.

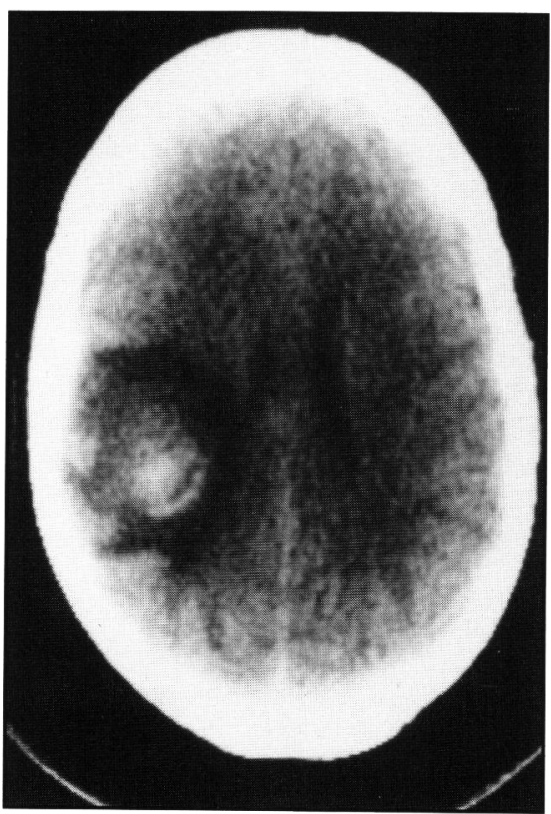

Figure 3 - The third CT scan was taken two years after the initial scans. There is a hemorrhagic infarction in the right fromto-parietal region. 
tous tissue, the ballooning leaflets promote damage to subendothelial connective tissue and platelet adherence. Large emboli may be seen in the angle between the mitral valve and the atrial valve. Other factors that may also contribute include abnormality of platelet function, 8 increased incidence of tachyarrhythmias and the danger of subacute endocarditis with septic embolization.

The reasons why some patients with MVP develop complications and others do not is uncertain. The development of complications could in part be explained by structural differences such as the degree of prolapse, the extent of myxomatous degeneration, and single versus bi-leaf prolapse. Nishimura et al have recently reported that initial ventricular diastolic dimension exceeding $60 \mathrm{~mm}$ across the open mitral valve may be the best indicator of potential complications and the subsequent need for mitral valve replacement. ${ }^{9}$ of 97 patients with redundant mitral valve leaflets identified on echocardiography, ${ }^{10}$ (10.3\%) developed ischemic cerebral events versus only one in $140(0.7 \%)$ of subjects with nonredundant mitral valves. This difference was statistically very significant ( $P$ less than .001 ). Berletta and associates have noted that patients with MVP and cerebral events have a higher incidence of associated aortic valve prolapse and valvular thickening. 10

Most information regarding risk reduction of systemic embolization with anticoagulation comes from studies of patients with myocardial infarction. Wright et al found a sevenfold reduction of cerebral emboli in a study of 1,031 postmyocardial infarction patients, 589 of whom were anticoagulated. 11 Similarly, Harvald et al found an eleven-fold reduction in stroke in their randomized study of 315 patients following myocardial infarction. ${ }^{12}$ Data on recurrent cerebral emboli and anticoagulation are limited. Although our experience is limited, an increase of the prothrombin time from $1 \frac{1}{2}$ times control to $21 / 2$ times control with an addition of aspirin seemed to stop recurrent events in our first patient. We would therefore recommend increasing the prothrombin time and if that does not seem to prove helpful, add aspirin to the treatment protocol.

\section{REFERENCES}

1. Barnett HJM, Jones NW, Boughner DR, et al. Cerebral ischemic events associated with prolapsing mitral valve. Neurology 1976; 26: 777-781.

2. Wolf PA, Sila CA. Cerebral ischemic events with mitral valve prolapse. Am Heart J 1987; 113: 1308-1315.

3. Cook AW, Bird TD, Spence AM, et al. Myotonic dystrophy mitral valve prolapse and stroke. Lancet 1978; 1: 335 .

4. Schnee MA, Bucal AA. Fatal embolism in mitral valve prolapse. Chest 1983; 83: 285-287.

5. Geyer SJ, Franzini DA. Myxomatous degeneration of the mitral valve complicated by non-bacterial endocarditis with systemic embolization. Am J Clin Pathol 1979; 72: 489-492.

6. Bramlet DA, Dicker EI, Floyd WL. Non-bacterial endocarditis as a cause of stroke in mitral valve prolapse. Southern Med J 1982; 75: 1133-1135.

7. Jackson AC, Boughner DR, Barnett HJM. Mitral valve prolapse and cerebral ischemic events in young adults. Neurology 1984; 34: 784-787.

8. Steele $P$, Weily $\mathrm{H}$, Rainwater J, et al. Platelet survival time and thromboembolism in patients with mitral valve prolapse. Circulation 1979; 60: 53-45.

9. Nishiuma RA, McGoon MD, Shub C, et al. Echocardiography documented mitral valve prolapse: Long term follow-up of 237 patients. N Engl J Med 1985; 313: 1305-1309.

10. Berletta GA, Gagliardi R, Benviti L, et al. Cerebral ischemic events as complication of aortic and mitral valve prolapse. Stroke 1985; 16: $219-223$.

11. Wright IS, Beck DF, Marple CD. Myocardial Infarction. Its Clinical Manifestations and Treatment with Anticoagulants. New York: Grune and Sutton 1954.

12. Harvald $B$, Hilden $T$, Lund $E$. Long-term anticoagulant therapy after myocardial infarction. Lancet 1962; 2: 626-630. 